\title{
UPDATE ON NATIONAL DEVELOPMENTS IN
}

\section{GRADUATE EDUCATION}

\author{
Robert E. Barnhill \\ NSF/CGS Dean in Residence \\ Past President and Senior Scholar, KU Center for Research \\ Professor, Mathematics and Electrical Engineering/Computer Science \\ University of Kansas
}

Last summer's Merrill Center research policy conference was entitled, "Recruiting and Training Future Scientists: How Policy Shapes the Mission of Graduate Education." I wrote an article, "Is Academic Research Sustainable?" for the proceedings of that meeting and described some national and local trends in university research.

During the past year I have been the National Science Foundation/Council of Graduate Schools Dean in Residence in the Division of Graduate Education at the NSF, an appointment that was initiated by discussions with CGS President Debra Stewart at last summer's Merrill Center policy meeting. This brief note is devoted to national issues in graduate education.

During the past year I co-organized and co-chaired a workshop on "Support of Graduate Students and Postdoctoral Researchers in the Sciences and Engineering: Impact of Related Polices and Practice," with Dan Stanzione, AAAS Fellow at the NSF Division of Graduate Education. The NSF, NIH and CGS sponsored the Support Workshop. Approximately 100 graduate students, postdoctoral researchers, faculty, graduate deans, labor economists and federal agency representatives attended the $1 \frac{1}{2}$ day workshop on June 17-18, 2004 in the AAAS Building in Washington, D.C.

Here I briefly recount the findings of that workshop. I also connect events from that workshop with presentations made at last summer's Merrill Center meeting.

At the summer 2003 Merrill Center policy meeting, CGS President Debra Stewart enumerated the following four major challenges in graduate education: curriculum reform, Ph.D. quality assessment, funding policy and post-9/11 policy. The Support Workshop touched on the first three of these challenges, with its principal emphasis being the third challenge - funding policy. Debra Stewart mentioned challenges in the funding of graduate students stemming from stipends that were too low as well as concerns caused by the recent doubling of NSF stipends in a small set of fellowship/training programs. (There are 5000 students in these particular NSF programs - about $20 \%$ of the graduate students supported by the NSF and about $2 \%$ of the national 
population of science and engineering graduate students.) The Council of Graduate Schools annually asks Graduate Deans for their top three concerns. Until the last couple of years, the number one concern was graduate student support. (Recently that topic has fallen to number two as the considerable decline in state support of universities has threatened the whole state university enterprise.) Several additional themes from the 2003 Merrill policy meeting were also featured in the Support Workshop, including diversity as mentioned by Suzanne Ortega and me, an NSF GK-12 project (one of the programs favored by the increased stipends) by Diandra Leslie-Pelecky, and several of the summarizing statements by Martha Crago.

Several members of the five Midwestern four-corners universities represented at the Merrill policy meetings - the University of Kansas, Kansas State University, the University of Nebraska, the University of Missouri and lowa State University - had members at the 2003 Merrill conference, the 2004 Merrill conference and the Support Workshop. These included: Ron Trewyn from Kansas State University, Prem Paul from the University of Nebraska, Suzanne Ortega from the University of Missouri-Columbia, Jim Bloedel from lowa State University, and I represented the University of Kansas. Thus our four-corner universities were well represented in this national discussion.

The Support Workshop was designed to address various aspects of financial support for U.S. citizens, science and engineering graduate students and postdoctoral researchers. Of the many stakeholders in American science and engineering, we focused on universities and federal agencies, although foundations and industry also had some representation in the workshop. Labor economist Richard Freeman was engaged to complement NSF statistical reports on science, technology, engineering and mathematics (STEM) workforce issues. Prior to the workshop, we held focus group sessions with the following sets of people: graduate deans, the National Postdoctoral Association, graduate students, the Council of Scientific Society Presidents (Marty Apple, who spoke at the 2002 Merrill Center policy meeting, is President of the CSSP), and AAAS Fellows.

The specific goal of the workshop was to consider the role and impact that financial support plays in encouraging U.S. citizens to enter STEM fields.

Let me cite a few of the particularly interesting findings from the $1-1 / 2$ days of discussions:

Alan Leshner, Executive Director of the AAAS, observed that nowadays graduate study and postdoctoral training account for about 10 years of a 40-year scientific career, that is, one fourth of the whole career, which has a definite effect on lifetime research accomplishments. Because it is the first quarter of a career, and graduate students and postdocs are poorly paid, this long period has career-long financial implications, as well. 
Labor economists at the workshop observed that the quality of graduate students declines as the number of awards available to them increases. Harvard economist Richard Freeman emphasized that the U.S. currently depends upon a "cheap" labor pool of graduate students and postdocs to accomplish much of its academic research. He and others suggested the idea, for graduate study, of a 5-year end-to-end support agreement with students. This could have several different components, mirroring the current situation in which students average 2.5 different types of support (research assistantships, teaching assistantships, fellowships, traineeships, self-funding).

$>$ The focus groups including the graduate students, postdocs, and AAAS Fellows agreed that the most important uncertainty for them was the length of time to, and uncertainty of obtaining, their first professional position. Money along the way is important, in that too little drives prospective STEM students out of the field. There are also probably differential effects of money for encouraging or discouraging minorities and females to enter STEM fields. Lack of health care can also drive graduate students and postdocs out of the profession.

The co-chairs, Dan Stanzione and I, concluded that the single most important message from the workshop was that the attractiveness of early professional careers in STEM must be systemically addressed. We believe there is a national disconnect between the desire to benefit from a cheap, young labor force for research (graduate students and postdocs) and the imperative to make STEM careers attractive to young people.

Finally, there is a continuing national debate on the question: Are there too many or too few STEM graduates? The answer is yes to both possibilities. There are too many graduates narrowly trained for academic activities and/or in areas that are already overflowing with students; there are too few graduates if we consider the broader national and societal problems that must be addressed.

Considerable additional information, including the agenda, list of participants, copies of all presentations and handouts, and a bibliography is available at: http://www.ehr.nsf.gov/dge/support workshop/index.html.

See the Merrill Center website for its research policy publications: www.merrill.ku.edu

\section{Conclusions}

National policy on important topics can be affected by small groups of people (cf. the concept of a "tipping point"). Thus, in this example, last summer's Merrill Center meeting about graduate education has led directly to an influence on the national conversation about the role and importance of financial support for graduate students and postdoctoral researchers in STEM fields. 
It is in the national interest to produce high quality research in science and engineering. Economists tell us that an inexpensive labor force of graduate students and postdocs makes achieving this goal easier; however, the lack of a defined time to a good first professional position deflects many U.S. students from these careers. These opposing forces must be understood, and then better managed, for a sustainable, robust American future in science and engineering. 